\title{
European Polymer Congress EPF2019
}

\author{
Spiros H. Anastasiadis ${ }^{1,2} \cdot$ Kiriaki Chrissopoulou $^{1}$
}

Received: 15 January 2021 / Accepted: 16 January 2021 / Published online: 2 February 2021

(C) The Author(s), under exclusive licence to Springer-Verlag GmbH, DE part of Springer Nature 2021



This special issue of the journal Colloid and Polymer Science is dedicated to the European Polymer Congress EPF2019, the biannual Conference of the European Polymer Federation, which was held in Hersonissos, Heraklion, Crete during 9-14 June 2019. The Congress was organized by the Hellenic Polymer Society (E $\Lambda \mathrm{E} \Pi)$, the Institute of Electronic Structure and Laser of the Foundation for Research and TechnologyHellas (FORTH-IESL), and the Department of Chemistry of the University of Crete.

The European Polymer Congress is the most important European Conference in the area of Polymer Science and Technology. It is the main conference of the European Polymer Federation, EPF, which is an umbrella non-profit organization of almost all National Polymer Societies in Europe. EPF was established in 1986 with 16 European Countries as founding members, whereas today, it includes 24 full and 4 associate members. The first EPF meeting was organized in Lyon in 1986, whereas the European Polymer Congresses were established as large scale events in 2001. Since then, the European Polymer Congress has become a

Spiros H. Anastasiadis

spiros@iesl.forth.gr

1 Institute of Electronic Structure and Laser, Foundation for Research and Technology - Hellas, P.O. Box 1385, 70013 Heraklion Crete, Greece

2 Department of Chemistry, University of Crete, P.O. Box 2208, 710 03 Heraklion Crete, Greece major biannual congress attracting an ever-growing participation. Besides being a scientific meeting, the Congress addresses other important issues such as education in polymer science and interactions between Academia and Industry. The success of EPF congresses proves the interest of the scientific and industrial community on the event, which covers all sides of polymer science and engineering and provides a forum for the whole European polymer community to meet and present the most recent cutting-edge research and industrial developments in this very important and active field.

EPF2019 brought together scientists working on macromolecular chemistry, physics of polymers and polymer materials, polymer surfaces-interfaces and thin films, polymeric nanostructured materials and nanocomposites, bio-based polymers and biocomposites, functional and smart materials, theory and simulations, modern applications of polymers, polymer reaction engineering, rheology and polymer processing, polymer characterization methods, etc.

About eight hundred of the most important polymer scientists from academic and research institutions and industry participated in the Congress. The delegates came from all European countries as well as from the USA, Australia, Korea, Japan, China, Taiwan, Brazil, South Africa, Canada, etc. The Conference program included 18 plenary lectures from worldrenown scientists, 56 keynote lectures given by distinguished scientists in the twelve thematic areas of the Conference, a Europe-Australian Symposium with 8 invited Speakers, a special session related to the RSC Polymer Chemistry Lectureship with 3 invited talks, as well as 308 oral presentations organized in 6 distinct parallel sessions. Moreover, there were 520 poster presentations by graduate students, $\mathrm{PhD}$ candidates, and postdocs. Poster awards were presented sponsored by the Royal Society of Chemistry ( 3 from the journal Soft Matter and 1 from the journal Polymer Chemistry), by Elsevier (1 from the journal Polymer and 1 from the journal European Polymer Journal), and by Springer Nature (3 from the journal Colloid and Polymer Science). Moreover, the journal Macromolecular Rapid Communications sponsored two plenary lectures.

This was the first time that the European Polymer Federation awarded the recently established EPF Prize. The Prize is awarded 
to recognize outstanding accomplishments and excellence in research in polymer science and contributions to the strengthening of the polymer science community. The 2019 EPF Prize was awarded to Prof. Ludwik Leibler from École Supérieure de Physique et de Chimie Industrielles de la Ville de Paris, France, "for groundbreaking contributions to the understanding of the phase behavior of block copolymers and for the discovery of new materials based on dynamic bonds like self-healing rubbers, vitrimers and tissue glues" during a special session on June 12, 2019.

This special issue contains nineteen papers, which were submitted by some of the Plenary and Keynote speakers of the Conference. The articles are either mini reviews or original research papers. There are papers on polymeric vesicles, on injectable hydrogels, on rheology and foaming of nanocomposites, on self-assembly of telechelic polyampholytes and star polymers, on responsive comblike macromolecules and polymer brushes, on nanoparticle surfactants, on novel natural polymer-based materials, on porous polymeric materials, on ferroelectric/semiconductive polymer blends, on ionic thermoelectric materials, on enzymatic transesterification of polyurethanes, on carrier transport in conjugated polymer films, on fluorinated electroactive polymers and fluorinated copolymers, on porous anodic aluminum oxide based nanocomposites, on biointerface engineering, and on polymers promoting/ inhibiting amyloid fibril formation.

We would like to thank all the contributing authors as well as all the reviewers for their help in organizing this special issue. Moreover, the support of the Editorial Office of Colloid and Polymer Science (Prof. Christine M. Papadakis and Prof. Annette Schmidt, Editors in Chief, and Prof. Friedrich Kremer, Chief Advisory Editor) and that of Dr. Christiane Brox, Associate Editor Chemistry, Polymer Chemistry, and Material Science of Springer Nature is highly appreciated.

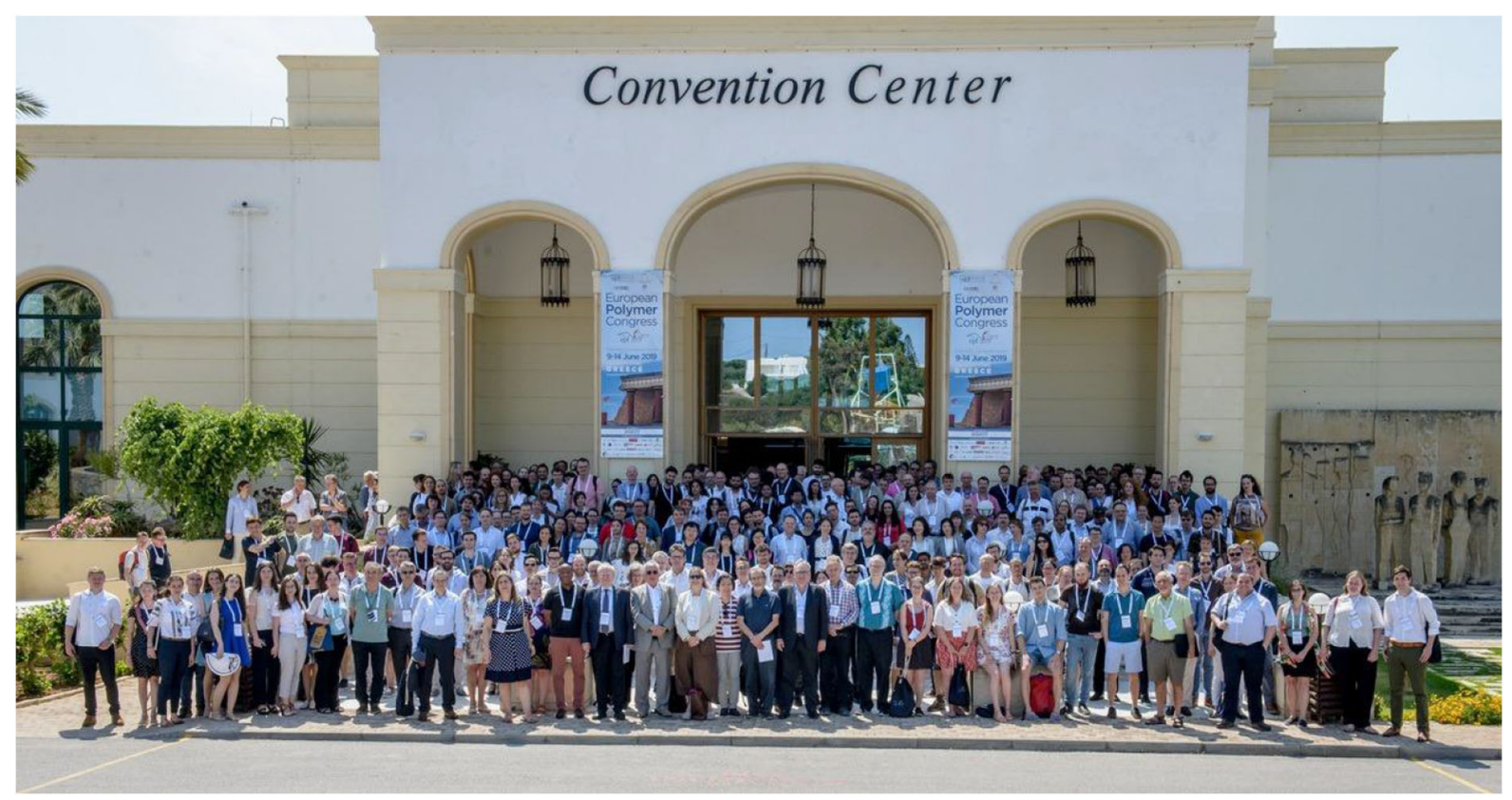

Publisher's note Springer Nature remains neutral with regard to jurisdictional claims in published maps and institutional affiliations. 